Article

\title{
Methods as Moving Ground: Reflections on the 'Doings' of Mobile Methodologies
}

\author{
Ingrid Boas ${ }^{1, *}$, Joris Schapendonk ${ }^{2}$, Suzy Blondin ${ }^{3}$ and Annemiek Pas ${ }^{4}$ \\ ${ }^{1}$ Environmental Policy Group, Wageningen University, 6706KN Wageningen, The Netherlands; E-Mail: ingrid.boas@wur.nl \\ 2 Geography, Planning, Environment Department, Institute for Management Research, Radboud University, \\ 6525AJ Nijmegen, The Netherlands; E-Mail: j.schapendonk@fm.ru.nl \\ 3 Institute of Geography, University of Neuchâtel, 2000 Neuchâtel, Switzerland; E-Mail: suzy.blondin@unine.ch \\ ${ }^{4}$ Department of Human Geography, Stockholm University, 10691 Stockholm, Sweden; \\ E-Mail: annemiek.schrijver@humangeo.su.se
}

* Corresponding author

Submitted: 4 June 2020 | Accepted: 21 August 2020 | Published: 19 November 2020

\begin{abstract}
As mobilities studies became a well-respected field in social science, discussions on mobile research designs followed. Usually, these discussions are part of empirical papers and reveal specific methodological choices of individual researchers, or groups of researchers sharing the same objectives and questions. This article starts with a different approach. It is based on continuous discussions between four researchers who developed their own version of mobility-driven projects, starting from different disciplinary backgrounds and using different research techniques. By sharing and contrasting personal fieldwork experiences, we reflect on the doings of mobile methodologies. We engage with the mistakes, dilemmas, and (dis)comforts that emerge from our own mobile research practices, and discuss what this implies for relations of power between the researcher and the research participants, and to what extent mobile research can represent the mobility that we seek to study. Specifically, the article addresses three questions: 1) To what extent do we produce different knowledge with our mobile methodologies? 2) How do our smooth writings about methodology relate to the 'messy' realities in the field? 3) How do our practices articulate and transcend difference between researchers and research participants?
\end{abstract}

\section{Keywords}

mobile methodologies; mobility; positionality; reflexivity; representation

\section{Issue}

This article is part of the issue "Method as Border: Articulating 'Inclusion/Exclusion' as an Academic Concern in Migration and Border Research in Europe" edited by Kolar Aparna (Radboud University, The Netherlands), Joris Schapendonk (Radboud University, The Netherlands) and Cesar Merlín-Escorza (Radboud University, The Netherlands).

(C) 2020 by the authors; licensee Cogitatio (Lisbon, Portugal). This article is licensed under a Creative Commons Attribution 4.0 International License (CC BY).

\section{Introduction}

The so-called 'mobilities turn' seeks to establish "a movement-driven social sciences" (Büscher \& Urry, 2009, p. 100), critiquing place-based and static understandings of social life and conventional approaches upholding to the confines of the nation-state (Davidson, 2020; Urry, 2007). This focus on the 'mobile' character of social life, and human mobility in particular, has led to the use of mobile methodologies. Researchers in this field study people or things on the move, including moments of blockage and voluntary or forced periods of immobility, using mobile methods such as 'moving with' people or objects, or digitally tracing these movements (Büscher \& Urry, 2009; D’Andrea, Ciolfi, \& Gray, 2011; Elliot, Norum, \& Salazar, 2017; Schapendonk, 2020; Schapendonk, Liempt, Schwarz, \& Steel, 2018; Spinney, 2011). Less known, however, is the practicality, and the 
wider academic implications, of using mobile methodologies (for notable exceptions see D'Andrea et al., 2011; Elliot et al., 2017; Merriman, 2014). Therefore, and in line with the main objective of this thematic issue, we reflect on the actual 'doings' and implications of these methodological approaches. More specifically, we relate mobile methodologies with the question of 'academic inclusion' (see Aparna, Schapendonk, \& Merlín-Escorza, 2020). While the four authors of this article all strongly value mobile research approaches, we came together to discuss our standpoints and insights regarding power and positionality (Faria \& Mollett, 2016) and the question of representation (Merriman, 2014), derived from our own fieldwork experiences. We asked ourselves: 1) To what extent do we produce different knowledge with our mobile methodologies? 2) How do our smooth writings about methodology relate to the 'messy' realities in the field? 3) How do our practices articulate and transcend difference between researchers and research participants?

In this article, these questions are not mechanically answered by the four authors but are implicitly and explicitly discussed through personal notes on the shifts, dilemmas and (dis)comforts of individual fieldwork. The first fieldwork note is on West African transnational mobility within Europe. The second focuses on environmentrelated mobilities in Bangladesh. The third involves a mobile auto-ethnography regarding domestic mobility in Tajikistan. The final fieldwork note discusses pastoral mobility in northern Kenya. By including our personal reflections on the four fieldwork experiences, we offer a heterogeneous picture of what insights, biases, divides and (dis)comforts are produced by mobile approaches. These reflections are then embraced as a 'critical mirror' to collectively discuss the promises and pitfalls of mobile research approaches. This discussion is not a simple consensus-driven exercise, but actually includes reflections on the positionality of each researcher vis-à-vis the other co-authors. The outcome of this discussion highlights how researchers can change and adjust their applied methods and 'move with' new ideas. This results in an invitation for more reflexivity in mobility research.

\section{2. 'Moving with' as a Research Methodology}

Mobile methods (Büscher \& Urry, 2009) and mobile methodologies (Elliot et al., 2017) are terms that became popularised in the course of the 2000s (e.g., Büscher \& Urry, 2009; D’Andrea et al., 2011; Hein, Evans, \& Jones, 2008). Büscher and Urry (2009) put forward a number of methods to move beyond the conventional, stationary methods of social science. These range from observing movements through participant observation, or audiovisual records of everyday mobility, to physically moving with a migrant, commuter, cyclist, container, or animal (see also Hein et al., 2008). While Büscher and Urry (2009) offer these methods in the context of the mobilities turn, it is important to note that research designs have (of course) not been completely blind to mobility (Benson, 2011). For anthropologists, evident points of reference are the widely discussed paper by Marcus (1995) - who advocates following the people, the thing, the metaphor, the plot, biography or conflict-and the work of Clifford (1997) on ethnography as a form of travel. Earlier research has also dealt with mobile people, including anthropological accounts of living and moving with those who live in mobility (e.g., Okely, 1983). One notable example is the work of Goldstein and Beall (1987, p. 2), who travelled with pastoralist groups in Tibet. They explicitly wrote about the practicalities of their mobility:

The widely scattered nomad campsites required us to move our camp frequently in order to obtain a meaningful sample. We hired yaks from the nomads to move our tent and equipment, but yaks are rather unruly animals and frequently threw off our loads damaging quite a bit of our equipment. It also often took days to arrange to hire these yaks (and horses) since they are normally left alone in the mountains quite far from the nomads' tentsites. For the next phase of the study we plan to buy our own horses and are making arrangements to hire our own caravan of yaks. We also will obviously have to make better carrying cases.

This quote illustrates that the mobility of the researcher is not merely a practical issue, but also-and inherently so-an intervention in 'the field.' The quote reflects the argument of Law and Urry $(2004$, p. 391) that methods are tools not only to "describe the world as it is, but also enact it."

The question of enactment-of bringing something into being-is particularly relevant for research approaches that seek to 'move with' people. There are two main concerns that are attached to the notion of enacting mobility. The first concern relates to positionality and representation of 'moving with' approaches. To understand its dynamics, mobility researchers often follow mobilities, or practice it themselves, in order to capture mobility in its full dynamism (see, for example, Spinney, 2011; for a critique see Merriman, 2014). In migration research, this resulted in so-called 'trajectory approaches' (Schapendonk, 2020; van Geel \& Mazzucato, 2018; Wilson, 2018) that produce a methodological shift from investigating migrants' position in a place, towards the "following of migrants through places" (Schapendonk et al., 2018). Central to these 'moving with' approaches are the practices and perspectives of the people on the move. These approaches offer insight into the everyday experiences of movement, or stillness, and from there it examines sites of struggle, marginalisation, duress or empowerment, in relation to other mobilities, networked actors or mobility regimes (Büscher \& Urry, 2009; Schapendonk et al., 2018). This ambition of 'capturing' the full dynam- 
ics of mobility, however, is simultaneously the main pitfall of a 'moving with' methodology. As ethnographic researchers, we often try to relate ourselves to the experiences of people on the move, to understand choices made and emotions felt. This brings us to the question of positionality.

As highlighted by Khosravi (2018) and Cabot (2016) in relation to refugees and forced migration, the question is: Can we-as privileged people working in academiareally know their experiences? Can we really put oneself in the shoes of the 'Other'? What do we know and what do we enact when researchers engage with less privileged mobility? When it concerns unauthorised movements, this might not only create uneven power relations, but it may even put people at risk. The researcher could enhance the "visibility of the migrant, which in turn increases the risk of being exposed to border patrols or being the target of extortion" (Khosravi, 2018). This demonstrates the need for constant reflection on part of the researcher in employing such methods. We cannot experience the world in precisely the same way as the people we study (Khosravi, 2018). Here mobility approaches might learn from a longer legacy of the discussion of politics of research relations in migration and refugee studies (Harrell-Bond \& Voutira, 2007; Malkki, 1995; van Liempt \& Bilger, 2009; see also Aparna, 2020).

Secondly, and closely related to the concern of representation, moving with individuals create its own biases. Following mobility might run the risk of either making assumptions for an entire community through a bias towards the one that is being 'followed.' In this regard, some scholars criticise the notion of transient and flexible communities in the context of so-called transit migration (Stock, 2019), as studies focusing on transit and onward movement overlook long-term community bonds in migrant groups in presumed transit locations. Other scholars encounter immobility and permanence in a presumed culture of mobility (Gaibazzi, 2015). In theory, mobility studies see mobility and immobility as dialectically constitutive (Wiegel, Boas, \& Warner, 2019), though in practice a 'moving with' approach risks ignoring these immobilities and, more specifically, the gendered notions of mobility/immobility relations (Reeves, 2011). In other words, who we follow (and who we do not follow) has implications for doing mobility research and the researcher's understanding of mobility processes.

To sum up, whilst much is written about 'moving with' research designs, and such methods are increasingly being applied in practice, this needs to be accompanied with active reflection by the researcher on the ethics, practicalities and limitations of such an approach. To add evidence to this, we present in the next sections our reflections on four fieldwork experiences using mobile methodologies. We seek to be transparent about our choices and own subjective understandings with regards to practices and experiences of mobilities.

\section{3. 'Doing' Mobile Methodologies: Fieldwork Reflections}

\subsection{Notes on Trajectory Research on West African Cross-Border Mobility within and beyond Europe (Schapendonk)}

There is something inherently odd with the approach of following people-an approach I advocated from the start of my academic work. Some of the oddness is part of fundamental ethnographic puzzles around relatedness, power and knowledge-others are specifically linked to the mobility involved. Below, I relate these issues to my research practices.

The trajectory ethnography that I developed is to a large extent built on the argument that migration studies start from sedentarist conceptualisations that 'exceptionalise' mobility (Schapendonk, Bolay, \& Dahinden, 2020). A mobility perspective enabled me to move away from the idea of the 'grant departure' of migrants (the presumed all-decisive moment of leaving one's place) and prevented me from falling into the 'happy ends' of place-bound integration and settlement. With this critique came the idea to follow migrants through space and time, in order to better understand mobility processes at the moments they actually unfold. But this 'moving with' approach runs the risk of reproducing the spectacular image of migration. In my PhD thesis, for example, I used the typical image of African migrants climbing the Ceuta fences. Although I related this image to the argument that we should not focus on these moments only, I now regard this image as a critical mirror since it does portray mobility as something problematic, exotic, exciting and political. As if we indeed need to grasp it (Aparna, 2020, based on Glissant) in order to normalise it. In my later work on the intra-EU mobility of West Africans, this mundane search for spectacular mobility lasted, although in less explicit ways. I remember my excited voice when one of my interlocutors 'reported' on his most recent irregular border crossing. Why do I (almost automatically) think these are the moments we should write about? Why are these spectacular crossings more important than the everyday commuting of borders that I also came across? A first reply could hint at the politics of mobility. The argument then is: Since these border crossings are unauthorised, they articulate the politics of mobility as they reflect the unequal distribution of mobility rights. But do they really? I mean, some of my interlocutors did not feel excited at all when they crossed borders in Europe without papers. One particular man actually fell asleep during his unauthorised train travels from Italy to Germany in the 'heat' of the so-called migration crisis. To my asking what actually happened en route, he simply replied: "Nothing really happened." Equally so, other people were confronted with immobility on their daily pathways to their work. They needed to wait for transport, some hitchhiked, and again others walked long distances to 
reach these places. These politics of mobility, however, are seen (by me and others) as less significant, often without any further justification.

The latter hints at the issue of relatedness. I consider my research as a product of relations, rather than a phenomenological representation of their mobility (Schapendonk, 2020). Yet, there were so many moments whereby any ground for relatedness between me and my interlocutors was difficult to find-situations of anxiety, risk and xenophobic violence. In my recent book (Schapendonk, 2020), I discuss and unpack these moments of un-relatedness, as it articulates what our boundaries are in terms of knowledge production.

The actual doings of the trajectory ethnography involved much travelling: I followed, among others, people's trajectories between Germany and the Netherlands, Spain and Italy, Italy and Switzerland, the Netherlands and the Gambia. The revisiting of people in different places is facilitated by the numerous in-between communications and a lot of hanging around with people. These longitudinal engagements are, of course, selfselective. I was dependent on the willingness of the people I worked with to answer my calls and messages. The stiffer social relations, the easier research relations collapsed. To put it differently, I ended up 'following' people on the basis of 'liking' each other (see also Lems, 2020). These bonds-some lasting for over a decade now-form fruitful grounds for insightful discussions on borders and mobility. The actual re-visiting of people in different places is, in general, a helpful way of producing stronger bonds and friendships. Ontologically speaking, these engagements formed a floating topology (Simone, 2019), as they not only helped me to construct an alternative worldview regarding mobility in contemporary Europe, but they also served mobility for me and my interlocutors. Through these relations possible travel destinations were discussed and new connections were made (Schapendonk, 2020).

The mobility involved comes with substantial personal inconveniences. As a father of two, I had to leave home many times in rather spontaneous ways. Following trajectories is in that sense a method that is difficult to plan beforehand, as it depends so much on the mobility of others. Also in terms of knowledge creation, there are clear downsides. I built only limited knowledge on 'local contexts' - and contextualisation is still seen as the main form of authority in ethnographic writing. At the same time, my travels between different places created something that I highly value, namely a space that unfreezes migrant positionalities in Europe today (Schapendonk, 2020, p. 198). Despite this unfreezing, it is of crucial importance, however, to not overlook people's unchanging situations. My re-visits to the people who did not move within Europe are in that sense equally valuable. Here I think of Shakur-a Gambian young man who got stuck in Italy's asylum procedures. Between 2014 and 2018, I visited him several times in the same asylum shelter. From his position of immobility, he saw most of his friends move across borders, looking for opportunities elsewhere, living postnational lives in Europe. From his static position, he saw the world moving around. We should, therefore, not ignore how place-based research designs (Gielis, 2009) add to our understanding of mobilities.

\subsection{From 'Moving with' to Tracing Connections: Environmentally-Related Human Mobility in Bangladesh (Boas)}

In this fieldwork note, I reflect on my study of rural coastal communities in Bangladesh, which have to move in the context of environmental changes (Boas, 2020). Initially the intent was to move along with environmental migrants while conducting semi-structured interviews with them (Boas, 2019). This was associated with a particular view on how environmental migration looks like. I anticipated it to be feasible to identify people moving in the context of environmental changes, but this turned out not to be the case.

Especially in the context of gradual environmental changes (such as coastal erosion), the need to move is not always immediate (on slow displacement see Carte, Schmook, Radel, \& Johnson, 2019). Deciding on the possible need to move could take months, or even years (Boas, 2020). As such, it would be very rare to meet someone moving away to a new place-as this consists of a long-term period of deliberation and planning. Also, when people move, it is often individuals or specific families who move, rather than entire groups or villages, as gradual environmental changes do not affect everyone at the same time. The migration dynamics are, as such, rather fragmented, as opposed to taking shape as a clearly identifiable stream.

That I fell into the trap of thinking that there would be easily identifiable 'flows' of environmental migrants, reflects the 'exceptionalisation' of mobility, as discussed in the above note on African (im)mobility. I had put a generalised, often media- and political-driven, label of migration upon this subject of environmentally-related human mobility, assuming a 'grand departure' with collectives of people moving. This does not mean that I was, per se, underprepared-I had undertaken substantial literature study and had in preparation actively engaged with local partners, who pointed me to areas where people are affected by environmental changes in their mobility. It is rather that environmental mobility is a relatively new area of research, in which both policymakers, NGOs, and researchers (including local ones), are still often driven by assumptions which turn out to be invalid when delving into messy empirical realities.

To account for this different reality, I re-oriented from 'moving with' a person to re-tracing or pre-tracing migration trajectories (including imagined and planned ones), with the use of more traditional place-based interviews. This meant studying how people draw on social network ties to enable their decisions to move, using mobile tech- 
nologies (Boas, 2020). For example, if I met someone planning to move to a certain place, I would travel to meet their contacts in that other place, to better understand their connection and what they imagined the shift to look like. I would use public transport to undertake the journey, to experience how they travelled there. Through face-to-face and digital exchanges with those I met during the research, though not always successful, I tried to verify if they were still accepting of me tracing their trajectory; not just by stating yes or no, but also by sensing whether someone felt uncomfortable talking to me or, more obviously, did not pick up the phone. Just like in the above field notes, I also experienced that friendships emerged out of some of these encounters, especially when tracing someone's trajectory for a long period of time. This also raised questions as to when the research ends or enters a more private domain of trustbased on friendship.

Generally, this shift from 'moving with' to (re/pre-)tracing trajectories, has helped me to better understand what environmental-related mobility entails. For example, one of the trajectories I traced involved a group of mostly women and children living in a heavily affected area of the island of Kutubdia, in the southeast of Bangladesh, in which most of the agricultural fields have been destroyed by incoming seawater (Boas, 2020). A number of male farmers from that area have already travelled to the mainland for work. The women who remained have taken the initiative in the search for a safer home. Most want to move to Chakariawhich is a hilly and green area on the mainland, close to Kutubdia island. One of these women is Morsheda. I met her in 2017 when she was trying to secure a house in Chakaria. She and her sister-in-law, Kadiza, who already has a temporary house in Chakaria, called each other daily for small talk, but also to discuss progress on a potential move (Boas, 2020). To get a better sense of Chakaria, I visited Kadiza's house, about four hours travel from Morsheda's house using local public transport and a boat. It was a temporary construction looking somewhat like a tent made from plastic, erected on the side of someone else's home. Morsheda and Kadiza were determined to find a more permanent home in Chakaria where they both could live. They would view different pieces of land where they potentially could live. In 2017, it all appeared very uncertain whether this move would transpire. In November 2019, I returned to Kutubdia. Morsheda had news. Together with Kadiza and two other neighbors they bought a piece of land in Chakaria. Kadiza and her family live there on a permanent basis, and the three other families can make use of it when the flooding is severe.

From tracing these connections, and by following up on Morsheda's story over the long-term, a different image of environmental mobility emerged, contrary to expectations. As opposed to moving away on a permanent basis or long-distance, this case instead finds a more ad-hoc temporary displacement strategy that al- lows those involved to collaboratively stay in their places of origin, whilst having an opt-out in times of emergency. This shows how assumptions about mobility are often misplaced, and that an effective mobile methodology requires constant interaction within the context of the research.

\subsection{Autoethnography as a Research Method of Local Im/Mobility Uncertainties in Tajikistan (Blondin)}

This third fieldwork note focuses on the environmentmobilities nexus at different scales in the mountains of the Viloyati Muxtori Kuhistoni Badakhshon (Autonomous Province of Mountainous Badakhshon), in Tajikistan. The aim was to understand the consequences of avalanches, rockslides and floods for populations living in the villages of the Bartang Valley, located between 2200 and 3100 meters above sea level, which are particularly remote. Journeys to villages of the middle and upper parts of the valley are full of uncertainties given the frequency of environmental hazards, the absence of public transport, the low motorisation rate and, particularly, the bad state of both vehicles and roads. In the absence of any public transport, the Bartangi use private shared cars to go to the city (mostly Khorog, the provincial capital). Drivers work according to a weekly schedule and leave once cars are full. I have used such cars to go to the Bartang Valley and to move around in the Valley. When no car was available, I have also shared long walking trips with local residents. Therefore, my journeys to the field have brought about various challenges such as finding a car, undergoing car repairs on the way, crossing flooded roads by car or on foot, organizing spontaneous sleepovers in the event of a breakdown, fighting feelings of anxiety about bad road conditions and staying patient in situations of strandedness.

Although I initially aimed to analyse the effects of environmental variability on permanent migration in the form of relocation, I quickly realised that local residents were more concerned about the effects of climate variability on mobility to the nearest town. When roads are blocked by avalanches, floods or rockslides, residents may face situations of involuntary immobility (Blondin, 2020). As such, I reoriented the research towards localscale mobilities and immobilities. With this new perspective in mind, my own experiences of journeys to/through the field became valuable research insights: what mobility options were available? How to find a seat in a car? How do cars manage the trip over hazardous terrain? How much time do trips take? As D'Andrea et al. (2011, p. 154) put it:

As 'getting there' and 'being there' are practical tropes of research feasibility and, in many cases, its own legitimacy, the research journey itself is permanently negotiated along the limitations, expectations and opportunities that end up constituting the actual field of research. 
Consequently, I have started to use auto-ethnography as "an excellent way to get at important aspects of human movement" (Vergunst, 2011, p. 203; see also Spinney, 2006). By auto-ethnography I refer to the ways in which my own mobilities, or reflections on my motility (mobility potential), became a method in itself to explore the mobilities of others. Auto-ethnography alone may have limited outcomes but since trips were always shared, it was accompanied by co-itinerant encounters and reflections: How do people move? How do people behave during trips? For instance, I witnessed how the most physically-vulnerable individuals complained about the effects of poor road conditions or worn-out vehicles on their bodies, and travellers praying before a departure and/or chatting throughout about common acquaintances. My own embodied experiences constituted a valuable first approach to understanding the ways in which people accessed mobility options, the skills needed to be mobile and how mobilities were appropriated by different residents.

Reflecting on my own experiences of mobility has been productive when comparing them with my fellow travellers' perceptions during informal conversations and interviews. This approach provided valuable results in terms of acknowledging the unevenness of our motilities (Blondin, 2020). Often, I was more scared by road conditions than my fellow travellers, who insisted that they were "used to the road" and that they were relying on their barakat (spiritual protection). After several trips in the region, I could feel that I was getting accustomed to mobility conditions and dangers and a fellow traveller told me: "I can see in your eyes that you are not scared anymore. You have gained some Bartangi barakat!" In addition, long walks between villages when no car was available have always been good occasions to compare my (physical) condition with my fellow travellers,' and allowed me to understand more accurately the difficulties of such trips: "The continuing relevance of bodily skills in ethnography, even in these globalised and 'systematised' times, reflects the significance such skills still have in everyday life too" (Vergunst, 2011, p. 216). I felt that my motility was weaker than my companions' because I initially had no experience in such context, or because I was not so good at handling involuntary immobility. But there were also issues that made me privileged in terms of motility when, for instance, I could afford to pay for 'the entire' car, which speeded up my departure if I needed to leave a village quickly. Usually, travellers share a car (like a local taxi) that only departs when all seats are taken. Auto-ethnography and co-travelling made me reflect on what shapes motility in my research context and how uneven mobilities emerge. Although the researcher's experiences cannot be confounded with the experience of research participants, a "kinaesthetic and embodied approach" (Spinney, 2006)-giving emphasis to the sensuous and real-life experiences of journeys-has a clear heuristic potential by offering a more comprehensive view of the mobilities under study.

\subsection{Reimagining Mobile Ethnography in the Case of Pastoralism (Pas)}

The final note focuses on the study of the mobility of pastoralists in northern Kenya. My aim was to understand how the mobility of pastoralists is transformed in relation to the (re)shaping of territories and access to and control of resources (Pas Schrijver, 2019). Here, recent shifting weather conditions and increased (inter)national investments in nature and wildlife conservation on community land in the pastoralist regions have resulted in mobility becoming more complex (Pas, 2018; Pellis, Pas, \& Duineveld, 2018). I studied the case of semi-nomadic Samburu pastoralists at the intersection of three counties: Laikipia, Isiolo and Samburu, within the greater Ewaso Nyiro River Basin.

Here, Samburu pastoralists move with livestock in search of pasture and water. Although based on substantial literature study and initial planning through active engagement with local partners and experts, my choices and assumptions during the preparation stage of my fieldwork - similar to the first two cases of this articlereflected a somewhat presumptuous understanding of mobility. In the preparation phase, I imagined I could join Samburu pastoralists and their cattle at their grazing sites. Yet, starting fieldwork in 2015, I learnt quickly that most of the Samburu cattle, and their herders, were not at home. It was considered an extremely dry year: The cattle had not been home since September 2014 and were in areas considered remote and dangerous. Contrary to what I had imagined, there was not a clearly identified group of people starting their journey who I could 'follow.'

I soon realised that current livestock mobility in Kenya works differently than I had anticipated. Longdistance mobility occurs in relation to specific points of interest which are unevenly spread around the landscape. There is not a final destination, as each point is a destination on its own, making livestock mobility highly patchy and uneven in space and time. What is more, I learned that mobile engagements were insufficient to understand the dynamics of pastoral systems and the environments in which they exist. It is often only a section of the community who will move with the cattle, rather than entire families. Samburu divide their families between those who stay with camels and small stock (sheep, goats, donkeys), often women, children and elder men; and those who move with cattle to faraway places for long periods of time, which are generally the morans (young unmarried man between the age of 15 and 30 years), who will live in temporary cattle camps. It was not a good idea to join the morans in faraway and often unsafe places, and besides, Samburu pastoralists are more than only on the move.

Therefore, instead of moving in real-time with the cattle and their herders during long-distance livestock mobility, I remained at certain locations. I adapted my research approach to include interviews focusing on nar- 
ratives which tried to reconstruct past routes and current pathways of livestock movement. My questions revolved around livestock mobility (not only cattle), access transformations, and how that articulated with the (im)mobility of people. This meant approaching people of different genders and age, discussing how regions were accessible in the past and which processes led to certain forms of exclusion. For example, I talked with Baba Lenketoi from Lekiji, a 74 year-old elder, about his moranhood. During those times, the entire family would continuously move short distances with their livestock. As a moran, Baba Lenketoi would only seldom separate from the rest of the family to go with the cattle and other morans to temporary cattle camps. These moments were like an adventure, in contrast to the morans today, who are mainly spending time in cattle camps far away from home. I also talked with mama Lenkas, who told me that 2015 was the first year she went with her goats to a temporary camp. There was a lack of foraging at home for the goats, therefore the women could not stay close to home either.

Still, the morans, who are responsible for moving the cattle to faraway places, remained important to my research. Yet, it was particularly hard to talk with morans, who are subject to strict regulations on how to interact in society (Spencer, 1973). The cultural conduct of a moran entails that they cannot be seen eating or drinking by women, other than a mother of another moran while he is also present. Also, although allowed to talk to women, morans are not known for being very talkative. I had the luck to be with Daniel the research assistant from Samburu who was a moran himself. Daniel was key to my access to other morans, and enabled conversations with them. Still, to get morans to talk, I had to prove that I was physically capable of walking. I joined for short-distance daily walks and they became more talkative over time. In addition, although morans were not supposed to consume food and beverages in front of me, there were moments when (not upon my request) elders negotiated and I, as a white, European, female scholar, was invited to be present at a meal. Slowly my presence was accepted, and morans were joking, considering me a moran so they could enjoy their tea in my presence. This shows how my whiteness, education and privilege facilitated access to groups and, therefore, my research in multiple ways (see Discussion section for further reflection on the role of privilege and this gender negotiation process).

All in all, this experience demonstrates that what and/or who you follow has implications for what and/or who you do not follow. My intent to 'follow the cow' would have primarily given me insights from the perspective of morans and their cattle, whereas livestock mobility in the Samburu context is more complex. It is interrelated to other people and aspects, such as the increasing importance of women moving with goats, and related dynamics, which my original approach would have overlooked. Situating myself in certain, static, locations not only provided me with different images of the daily realities of livestock mobility, it also indicated important ongoing shifts in the mobility patterns of the Samburu.

\section{Discussion}

The above fieldwork notes offer an account of the actual 'doings' of mobile methodologies, and how they relate to the questions of academic inclusion and representation. It is important to stress that-although we share an itinerant research approach-all four scholars have different backgrounds and positions in academia. While writing this article, we also noticed that we held different standpoints regarding how we value mobility and how we see the role of the researcher in studying these processes (see Box 1). Here we highlight some of our main

Box 1. Quotes of the authors mirroring our different positionalities in the discussions.

“There is some 'eagerness' in Northern research agendas that I find problematic. Why do we need to break with social codes? Why not respect these codes and change our research ambitions?"

"Would declining invitations by local communities that could 'break the social code" not be 'breaking a code' as well? Aren't social codes always subject to change?"

"It might be that female researchers face more barriers in doing research of others' mobility if we should refrain from too much 'interference' with these 'social codes.' Since in at least most of our cases, much of the mobility mainly included males, with the women more in place."

"Although mobility capitals will never be equal, sharing a sometimes long or difficult journey is a way to form a group, to share experience and memories and may be a way to be more included in this community/group/population. But maybe I am too idealistic here?"

"The embodied and physical aspects of mobilities felt or undergone together, may also be a way to put power inequalities aside. Financial capital or a certain passport can't 'buy' or erase some of the physical challenges of certain trips, for instance." 
threads of reflection, that point to some of the synergies and frictions between the different positionalities.

On a practical level, our four cases show how the 'ultimate' mobile methods - that aim to capture mobility when it unfolds-are rather difficult to achieve or, more likely, do not exist. We touched upon different cultural expectations about who can move and we discussed how mobilities may actually entail long periods of immobility. This also underscored how mobility and immobility are closely interlinked (Wiegel et al., 2019), leading some of us to adapt our methodologies to do more research in place. The mobile approach may turn out to be more local than expected; more stable than expected; slower or more fragmented than expected, etcetera, requiring a constant need to adapt to these dynamics.

This need to adjust to mobilities' pace and direction makes us aware of the often-biased initial assumptions guiding research. All cases in this article illustrate how we expected to examine an exceptional form of mobility: such as the seemingly spectacular mobility of irregular border crossing, which later turned out to be mundane or even boring to those involved, or the expectation of grand departures, long-distance and forced migration, whilst for the people involved the simplest movement from home to town is most crucial and most affected. A mobility approach, then, first and foremost means a legitimation to move away from pre-set research designs, and an invitation to invent new research questions 'along the way' and align your 'doings' with the dynamics you encounter and the restrictions you face. Mobile methods form, in this sense, a moving ground. In doing so, it is crucial to be closely connected to local partners, to ensure the research is well grounded and adjusted to local contexts. Nonetheless, as noted in the second and fourth field case, this is no guarantee for a better planned methodology. Local researchers and organisations may also come from societal positions other than the research participants, and may therefore also misinterpret local meanings, especially in the context of not much researched topics. Also, independent of the preparations made, when embedding oneself in the research, new insights emerge along the way, which may require the research to shift course.

On an epistemic level, 'moving with' approaches entail a focus on embodied practices, sensations and the material aspects of mobilities. This gears attention towards the everyday, mundane, ordinary, superfluous and pre-cognitive aspects of mobilities (Adey, 2017; Davidson, 2020). Even when examining the 'exceptional' side of mobilities, our focus on the everyday doings made us shift to its mundane aspects. However, as discussed by Merriman (2014), mobile methods implicitly risk turning research projects into 'representational' projects. This becomes particularly uncomfortable in our cases, since we-despite our reflexivity and local preparations-still started from our default Western gaze with which we studied non-Western mobilities. A way forward could be the autoethnography, as de- scribed in the third fieldwork note, by which the researcher can use their own experiences of mobility and immobility and mirror it with the mobility of others (Cook \& Edensor, 2017; Spinney, 2006). In this way, observing fellow travellers or interviewing research participants about mobilities also practiced by the researcher may allow for interesting analytical comparisons. At the same time, as the first case articulates, we might encounter a fundamental lack of relatedness to do this. This raises the plea for a more modest ethnographic approach, in the sense that it should not necessarily be the main goal to 'capture' other people's experiences of moving (Cabot, 2016), as mobility research is often aiming for. This would be in line with Merriman's (2014, p. 176) argument that mobility is, in its essence, rather non-representational:

My experience of driving or passengering along a particular stretch of road is unlikely to be fully aligned with someone else's experiences, whether they are travelling along with me, or not. Physical proximity and co-presence present an illusion of 'firsthandedness,' closeness, accuracy and authenticity.

Moreover, by actively seeking to research another's mobility, we actually shape that mobility and trigger specific social transformations. We enact mobility (Law \& Urry, 2004). By researching people's im/mobility, we get to know these people, engage with them. This may influence mobility choices, practices and effects. This is not necessarily a bad thing, but it does indicate how mobilities are intertwined. What does this intertwining mean for the research and, more importantly, for the people we work with and write about? In the first case, the researcher saw the study of mobility as a product of the relations he built, but, in the end, it is still him writing about mobilities, showing the limitations of dealing with the intertwined character of mobilities. In the fourth case, the researcher felt well-embedded in the local community under research, while being approached differently by those studied as someone coming from the 'Global North.' During her activities, gender roles were renegotiated on the initiative of the pastoralist elders, which led to different social arrangements (e.g., being invited to eat with the young warriors), thereby allowing the researcher to build productive research relations with morans. Discussions with informants may even lead to new frames of mobility that may not necessarily be in line with their feelings and experiences. One telling example comes from the first project, where one the authors accompanied a Gambian man to the Duomo square in Milan. When he started to take pictures of the Duomo square, the researcher semi-jokingly referred to his tourist-like behaviour. For this informant, tourism was an entirely new framework with which to perceive his mobility in Europe.

Still, with this above notion of enacting, the question of consent becomes more complicated. How should 
we deal with informed consent when situations are on the move? As one of our anonymous reviewers posed: "Can refugees or undocumented migrants provide truly informed consent to participating in research, given the precariousness of their situations?" (see discussions in Harrell-Bond \& Voutira, 2007). Considering these challenges and sensitivities, it is, in our view, vital to remain reflective of the 'doings' of research, also in connection in relation to research participants, to make clear that the research itself is a process open to mistakes, change and contestation.

\section{Conclusion}

As mobilities studies became a well-respected field in social science, discussions on mobile research designs and mobile methods followed. Usually, these discussions were part of empirical papers and reveal specific methodological choices of individual researchers, or groups of researchers sharing the same objectives and questions. This article took a different approach. It is based on continuous discussions between four researchers who developed their own versions of mobility-driven projects, starting from different disciplinary backgrounds, having different research objectives, and having applied different techniques in the field. Although the writing process of this article was not always easy, the discussions were fruitful as they touched upon some of our implicit knowledge and biases.

In concluding, we would like to re-visit the questions we raised in the introduction. Firstly, in terms of whether we produce different knowledge, the four authors tend to agree (albeit for different reasons) that their mobile methodologies have great heuristic potential and provide different knowledge to place-bound and/or interview-based research designs. The methods used allowed the researchers (albeit to different degrees) to practice mobility and to reveal mobility-immobility relations that otherwise would remain hidden. All four projects went beyond ex-post reconstructions of people's movements, creating more space for, among others, ambivalence to, and redirections of, mobility. The second question on how messy realities relate to our methodologies critiques the notion that good research designs are pre-planned, fixed and inflexible. Research processes might themselves have an itinerant character (Aparna, 2020) and serendipity might indeed be much more valued in research approaches (e.g., Rivoal \& Salazar, 2013). Mobile methodologies allow for some space of openness, as researchers often do not know where they will end up, in both geographical and analytical terms. The final question relates to mobility as an unequally distributed resource. Our research relations articulated this difference, rather than providing a solution to it. Moving together may imply more intimacy and may deepen research relationships, which can help to create more transparency and reflection in the realm of research, including with the informants of the research themselves. At the same time, our relations with research participants remain unequal in terms of mobility potentials, and we may therefore not be able to fully represent their experiences.

In the end, we regard this article as an invitation to other researchers of mobility to contrast her/his own 'doings' with those of others. As in our case, that might entail showing mistakes or fallacies of the research, but at the same time allows research to remain self-reflective. This is not only valuable in terms of the transparency of specific methodologies, but it can also be a critical mirror for each person involved in this discussion and a way forward to address the politics of mobility. In the metaphorical sense-and we stick to mobility related terminology here-standing still in a process of movement can be very productive. This implies that we should not always go with the flow of the everyday, of larger PhD trajectories, or post-doc careers. We might stand still and ask ourselves what we are doing in the first place, and for whom.

\section{Acknowledgments}

We thank the participants of the "International Symposium on Environmental Change, Im/Mobilities, and Migration" held at Wageningen University (June 2019) for their feedback on our ideas; the anonymous reviewers for their suggestions to further improve the article; and Cebuan Bliss for editing our article to improve the English language. This research was funded by: Two Veni Grants of the Dutch Research Council (NWO, Grant Number: 451-16-030; 451-14-011); the Fonds des Donations of the University of Neuchâtel; a Marie Skłodowska-Curie Action "Resilience in East African Landscapes" (REAL) Innovative Training Network funded by the European Commission (FP7-PEOPLE-2013-ITN project no. 606879). The first two authors took the lead in constructing this article with an equal contribution.

\section{Conflict of Interests}

The authors declare no conflict of interests.

\section{References}

Adey, P. (2017). Mobility (2nd Ed.). London and New York, NY: Routledge.

Aparna, K. (2020). Enacting asylum university: Politics of research encounters and (re)producing borders in asylum relations (Unpublished Doctoral dissertation). Radboud University, the Netherlands.

Aparna, K., Schapendonk, J., \& Merlín-Escorza, C. E. (2020). Method as border: Tuning in to the cacophony of academic backstages of migration, mobility and border studies. Social Inclusion, 8(4), 110-115.

Benson, M. (2011). The movement beyond (lifestyle) migration: Mobile practices and the constitution of a better way of life. Mobilities, 6(2), 221-235. 
Blondin, S. (2020). Understanding involuntary immobility in the Bartang Valley of Tajikistan through the prism of motility. Mobilities, 15(4). https://doi.org/ 10.1080/17450101.2020.1746146

Boas, I. (2019). Using mobile methods to trace networks and connections: Environmental migration in the digital age. Thousand Oaks, CA: SAGE Research Methods Cases in Political Science and International Relations. Retrieved from http://methods.sagepub. com/case/mobile-to-trace-networks-environmentalmigration-in-the-digital-age

Boas, I. (2020). Social networking in a digital and mobile world: The case of environmentally-related migration in Bangladesh. Journal of Ethnic and Migration Studies, 46(7), 1330-1347.

Büscher, M., \& Urry, J. (2009). Mobile methods and the empirical. European Journal of Social Theory, 12(1), 99-116.

Cabot, H. (2016). "Refugee voices": Tragedy, ghosts, and the anthropology of not knowing. Journal of Contemporary Ethnography, 45(6), 645-672.

Carte, L., Schmook, B., Radel, C., \& Johnson, R. (2019). The slow displacement of smallholder farming families: Land, hunger, and labor migration in Nicaragua and Guatemala. Land, 8(6), https://doi.org/10.3390/ land8060089

Clifford, J. (1997). Routes: Travel and translation in the late twentieth century. Harvard: Harvard University Press.

Cook, M., \& Edensor, T. (2017). Cycling through dark space: Apprehending landscape otherwise. Mobilities, 12(1), 1-19.

D’Andrea, A., Ciolfi, L., \& Gray, B. (2011). Methodological challenges and innovations in mobilities research. Mobilities, 6(2), 149-160.

Davidson, A. C. (2020). Radical mobilities. Progress in Human Geography. Advance online publication. https:// doi.org/10.1177/0309132519899472

Elliot, A., Norum, R., \& Salazar, N. B. (Eds). (2017). Methodologies of mobility: Ethnography and experiment. Oxford: Berghahn Books.

Faria, C., \& Mollett, S. (2016). Critical feminist reflexivity and the politics of whiteness in the 'field.' Gender, Place \& Culture, 23(1), 79-93. https://doi.org/ 10.1080/0966369X.2014.958065

Gaibazzi, P. (2015). Bush bound: Young men and rural permanence in migrant West Africa. Oxford: Berghahn Books.

Gielis, R. (2009). A global sense of migrant places: Towards a place perspective in the study of migrant transnationalism. Global Networks, 9(2), 271-287.

Goldstein, M. C., \& Beall, C. M. (1987). Anthropological fieldwork in Tibet studying nomadic pastoralists on the Changtang. HIMALAYA, the Journal of the Association for Nepal and Himalayan Studies, 7(1), 1-4.

Harrell-Bond, B., \& Voutira, E. (2007). In search of 'invisible' actors: Barriers to access in refugee research. Journal of Refugee Studies, 20(2), 281-298.

Hein, J. R., Evans, J., \& Jones, P. (2008). Mobile method- ologies: Theory, technology and practice. Geography Compass, 2(5), 1266-1285.

Khosravi, S. (2018). Afterword. Experiences and stories along the way. Geoforum. Advance online publication. https://doi.org/10.1016/j.geoforum.2018.05. 021

Law, J., \& Urry, J. (2004). Enacting the social. Economy and Society, 33(3), 390-410.

Lems, A. (2020). Phenomenology of exclusion: Capturing the everyday thresholds of belonging. Social Inclusion, 8(4), 116-125.

Malkki, L. H. (1995). Refugees and exile: From "refugee studies" to the national order of things. Annual Review of Anthropology, 24(1), 495-523.

Marcus, G. E. (1995). Ethnography in/of the world system: The emergence of multi-sited ethnography. Annual Review of Anthropology, 24(1), 95-117.

Merriman, P. (2014). Rethinking mobile methods. Mobilities, 9(2), 167-187.

Okely, J. (1983). The traveller-gypsies. Cambridge: Cambridge University Press.

Pas, A. (2018). Governing grazing and mobility in the Samburu Lowlands, Kenya. Land, 7(2). https://doi.org/ 10.3390/land7020041

Pas Schrijver, A. (2019). Pastoralism, mobility and conservation. Shifting rules of access and control of grazing resources in Kenya's northern drylands (Unpublished Doctoral dissertation). University of Stockholm, Sweden.

Pellis, A., Pas, A., \& Duineveld, M. (2018). The persistence of tightly coupled conflicts. The case of Loisaba, Kenya. Conservation and Society, 16(4), 387-396.

Reeves, M. (2011). Staying put? Towards a relational politics of mobility at a time of migration. Central Asian Survey, 30(3/4), 555-576.

Rivoal, I., \& Salazar, N. B. (2013). Contemporary ethnographic practice and the value of serendipity. Social Anthropology, 21(2), 178-185.

Schapendonk, J. (2020). Finding ways through Eurospace. West African movers re-viewing Europe from the inside. Oxford: Berghahn Books

Schapendonk, J., Liempt, I., Schwarz, I., \& Steel, G. (2018). Re-routing migration geographies: Migrants, trajectories and mobility regimes. Geoforum. Advance online publication. https://doi.org/10.1016/ sj.geoforum.2018.06.007

Schapendonk, J., Bolay, M., \& Dahinden, J. (2020). The conceptual limits of the 'migration journey.' Deexceptionalising mobility in the context of West African trajectories. Journal of Ethnic and Migration Studies. Advance online publication. https://doi.org/ 10.1080/1369183X.2020.1804191

Simone, A. (2019). Improvised lives: Rhythms of endurance in an urban south. Cambridge: Polity Press.

Spencer, P. (1973). Nomads in alliance. Symbiosis and growth among the Rendille and Samburu of Kenya. Oxford: Oxford University Press.

Spinney, J. (2006). A place of sense: A kinaesthetic ethnog- 
raphy of cyclists on Mont Ventoux. Environment and Planning D: Society and Space, 24(5), 709-732.

Spinney, J. (2011). A chance to catch a breath: Using mobile video ethnography in cycling research. Mobilities, 6(2), 161-182.

Stock, I. (2019). Time, migration and forced immobility. Bristol: Bristol University Press.

Urry, J. (2007). Mobilities. Cambridge: Polity Press.

van Geel, J., \& Mazzucato, V. (2018). Conceptualising youth mobility trajectories: Thinking beyond conventional categories. Journal of Ethnic and Migration Studies, 44(13), 2144-2162.

van Liempt, I., \& Bilger, V. (Eds.) (2009). The ethics of migration research methodology. Dealing with vulnera- ble immigrants. Brighton: Sussex Academic Press.

Vergunst, J. (2011). Technology and technique in a useful ethnography of movement. Mobilities, 6(2), 203-219.

Wiegel, H., Boas, I., \& Warner, J. (2019). A mobilities perspective on migration in the context of environmental change. Wiley Interdisciplinary Reviews: Climate Change, 10(6). https://doi.org/10.1002/wcc.610

Wilson, M. C. W. (2018). Spatial mobility and social becoming: The journeys of four Central African students in Congo-Kinshasa. Geoforum. Advance online publication. https://doi.org/10.1016/j.geoforum.2018.05. 018

\section{About the Authors}

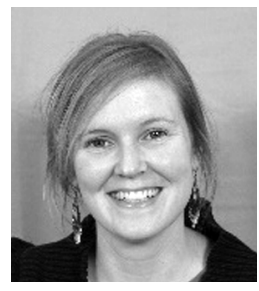

Ingrid Boas is an Associate Professor at the Environmental Policy Group of Wageningen University. She researches intersections between environmental change, mobilities and governance. In 2016, Ingrid was awarded a personal Veni Grant with the Netherlands Scientific Organization to study environmental migration in the digital age. Ingrid's work has appeared, amongst others, in Global Environmental Politics, the Journal of Ethnic and Migration Studies, Nature Climate Change, and in the monograph (Routledge, 2015) examining the securitisation of climate migration.

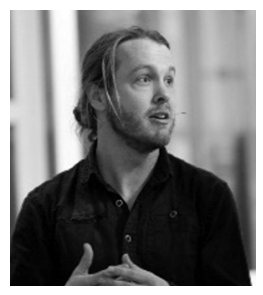

Joris Schapendonk is Assistant Professor at the Geography, Planning and Environment department of Radboud University and an active member of Nijmegen Centre for Border Research (NCBR). His research concentrates on im/mobility trajectories, borders and migration industries. His work is published in, among others, Annals of the Association of American Geographers (2014), Journal of Ethnic and Migration Studies (2018; 2020) and Geoforum (2018). His latest book, Finding Ways in Eurospace (2020), is published by Berghahn Books (https://www.berghahnbooks.com/title/ SchapendonkFinding)

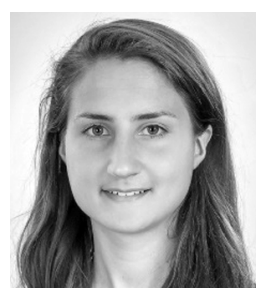

Suzy Blondin is a PhD Candidate and Teaching Assistant at the Institute of Geography of the University of Neuchâtel. Her doctoral work focusses on rural-urban mobilities in the Pamir mountains of Tajikistan. She focusses specifically on immobility, motility and place attachment in the context of environmental risks. Her work has recently been published in Mobilities and the Central Asian Survey.

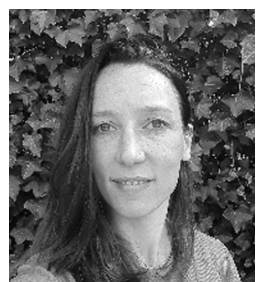

Annemiek Pas has recently finalized her PhD dissertation based on the shifting politics of pastoral resource access in relation to the large-scale establishment of community conservancies in Kenya. Building upon her past research in the realm of natural resources governance, she is interested to empirically study and theorise on processes of ongoing rural reconfigurations and evolving property regimes-at the interface of governmental policies and local realities-studying local communities' perceptions of, and responses to, these processes of change. 